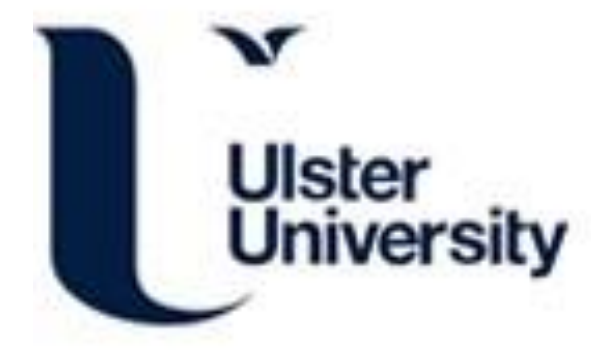

\title{
A Simplified Thermal Approximation Method to include the effects of Marangoni Convection in the melt pools of processes that involve moving point heat sources
}

Nikam, S., Quinn, JP., \& McFadden, S. (2021). A Simplified Thermal Approximation Method to include the effects of Marangoni Convection in the melt pools of processes that involve moving point heat sources.

Numerical Heat Transfer, Part A: Applications: An International Journal of Computation and Methodology, 79(7), 537-552. https://doi.org/10.1080/10407782.2021.1872257

Link to publication record in Ulster University Research Portal

Published in:

Numerical Heat Transfer, Part A: Applications: An International Journal of Computation and Methodology

Publication Status:

Published (in print/issue): 03/04/2021

DOI:

10.1080/10407782.2021.1872257

\section{Document Version}

Author Accepted version

\section{General rights}

Copyright for the publications made accessible via Ulster University's Research Portal is retained by the author(s) and / or other copyright owners and it is a condition of accessing these publications that users recognise and abide by the legal requirements associated with these rights.

\section{Take down policy}

The Research Portal is Ulster University's institutional repository that provides access to Ulster's research outputs. Every effort has been made to ensure that content in the Research Portal does not infringe any person's rights, or applicable UK laws. If you discover content in the Research Portal that you believe breaches copyright or violates any law, please contact pure-support@ulster.ac.uk. 
A Simplified Thermal Approximation Method to include the effects of Marangoni Convection in the melt pools of processes that involve moving point heat sources

Sagar H. Nikam ${ }^{1, *}$, Justin Quinn ${ }^{1}$, Shaun McFadden ${ }^{1}$

${ }^{1}$ School of Computing, Engineering and Intelligent Systems, Ulster University, Londonderry, BT48 7JL, Northern Ireland, UK

* Corresponding author: Sagar H. Nikam; Email: s.nikam@ulster.ac.uk; Address: School of Computing, Engineering and Intelligent Systems, Ulster University, Northland Road, Londonderry, BT48 7JL, Northern Ireland, UK 


\title{
A Simplified Thermal Approximation Method to include the effects of Marangoni Convection in the melt pools of processes that involve moving point heat sources
}

\begin{abstract}
Processes that use moving point heat sources to temporarily create localised melt pools (metal additive manufacture and fusion welding) have a flow phenomenon due to the surface tension gradient. Surface tension of the liquid metal reduces with temperature and this, coupled with the high temperature gradients associated with point heat sources, creates Marangoni convection in the melt. The Marangoni convection tends to reduce the temperature and change the melt pool geometry (increases width but reduces depth). Computational Fluid Dynamics (CFD) models can simulate the phenomenon of Marangoni convection but are computationally intensive. A simpler thermal model involving heat conduction and latent heat, but with the liquid's thermal conductivity artificially increased by a constant factor, exhibits similar thermal effects to the Marangoni convection. The heat conduction models are computationally less intensive that CFD, but the trial-and-error exercise needed to obtain an appropriate multiplying factor is time consuming. With an aim to improve the process of factor selection, the present study investigates the correlation between the surface tension gradient and correction factors. For a Ti-6Al-4V under typical additive manufacturing parameters, the corresponding correction factor to be applied to liquid thermal conductivity was 1.76 .
\end{abstract}




\section{Introduction}

Moving point heat sources used for solidification processing applications play an important role in metal Additive Manufacturing (AM) and fusion welding applications. The layer-on-layer deposition geometry in additively manufactured components and the bonding strength of joints in fusion welding applications are dependent on the formation and subsequent cooling of the melt pool by the action of the moving heat source. The melt pool formation and its flow dynamics represent some of the most critical phenomenon in fusionbased manufacturing processes [1]. The internal fluid flow behaviour of the melt pool is governed by several aspects such as the process parameters, material properties, fluid flow, buoyancy, etc. [2-4]. A key challenge in the study of melt pool dynamics is the accurate prediction of melt pool evolution and the estimation of melt pool shape and size [5]. To this end, computational modelling and simulation of melt pools has played a vital role [6-7]. To investigate the melt pool formation phenomenon with Computational Fluid Dynamics (CFD) modelling, researchers have developed non-commercial codes [8] and have used commercial software such as Fluent [9], OpenFOAM [10], COMSOL Multiphysics [11] and Flow-3D [12], among many others. However, the computational time associated with simulating via CFD methods can be too long and cumbersome. As a route to preliminary results within a shorter time frame, a heat conduction model may be used where the effects of fluid flow are neglected. Many researchers have proposed simpler heat conduction models using bespoke codes with, for example, Ansys Parametric Design Language (APDL) codes [13], ABAQUS [14], FORTRAN [15], COMSOL Multiphysics [16], etc.,

Marangoni convection is a phenomenon that occurs in metal melt pools when the surface tension of the liquid metal reduces with temperature and large temperature gradients exist within the melt pool. The surface tension increases radially outwards along the surface of the fluid as the temperature decreases. This increase in surface tension outwards from the centre 
of the heat source can cause fluid flow circulation called Marangoni convection. The Marangoni convection influences the temperature profile (by lowering the peak temperature and temperature gradients in the melt pool) and the melt pool geometry (by widening and reducing the depth of the melt pool). A heat conduction model will neglect the effects of Marangoni convection, but it is proposed [17] that the effects of Marangoni convection can be approximated in a heat conduction model by increasing the conductivity in the liquid region by some multiplying factor, $C_{m}$.

\subsection{Literature review}

An important phenomenon that governs the temperature distribution and dimensions of a travelling melt pool is the thermo-capillary flow phenomenon due to the surface tension gradients on the liquid surface called the Marangoni effect. Using commercial software, the Marangoni phenomenon has been simulated in two different ways: 1) in CFD modelling by defining the surface tension gradient to incorporate Marangoni convection and 2) in heat conduction model by modifying the value of thermal conductivity of the liquid phase with a correction factor.

Xiao and Zhang [18] developed a numerical CFD simulation to identify the effect of buoyancy and Marangoni on the shape of the melt pool. They provided simulation results for Selective Laser Melting (SLM) processes using finite volume methodology that predicted the internal flow of the melt pool. Khairallah et al. [19] investigated the effect of recoil pressure and Marangoni convection on the melt flow in the molten pool formed during SLM of 316L stainless steel using CFD. Here, they validated the simulation by investigating the effect of recoil pressure and Marangoni convection on the pore defects generated due to melt flow. By considering the complex phenomenon of the melt pool flow in the SLM AM process, Xia at al. [20] used CFD simulation using fluent software to investigate the porosity evolution and its distribution due to the thermodynamics of the melt pool. Heeling et al. [21] proposed a 
CFD model incorporating the physical effects of buoyancy, Marangoni, evaporation, recoil pressure and capillary effects. Many other researchers have proposed studies on the development of CFD models that primarily focus on the effect of Marangoni on the simulated temperature distribution and melt pool dimensions [22-24]. Jamshidinia et al. [23] used a 3D thermo-fluid Marangoni-driven flow model to investigate and optimize the process parameters of an Electron Beam Melting (EBM) process. Consequently, Kidess et al. [24] developed a direct numerical simulation to identify the effect of Marangoni driven turbulence on the melt pool shape formed during the laser welding process.

Simultaneously along with CFD modelling, researchers are also proposing the simple yet useful heat conduction models for $\mathrm{AM}$ and fusion welding processes. Therefore, to incorporate the effect of Marangoni in the heat conduction model, the value of the thermal conductivity above liquidus temperature has been modified by multiplying with some value of correction factor, $C_{m}$ [17, 25-29]. Lampa et al. [17] first suggested this method while developing an analytical model for laser welding process. Here they increased the value of thermal conductivity by a $C_{m}$ value of 2.5 . Using this method, they simulated the melt pool width and depth and found it to be in close agreement with experimental results. This value of correction factor has been found to be appropriate for the studies reported by Kumar et al. [26] and Nikam and Jain [27] in developing a finite element simulation for the laser-based rapid manufacturing and micro-plasma transferred arc additive manufacturing process, respectively. In the study reported by De and DebRoy [28] for developing a simulation for laser spot welding process. They identified that the selected value to modify the thermal conductivity in liquid phase was approximately equal to eight $\left(C_{m}=8\right)$. While Romano et al. [29], studying a laser-based additive manufacturing process, used a $C_{m}$ factor of approximately 15 . 
From the literature, it can be concluded that the CFD models have the capability to simulate the Marangoni effect in the melt pool but are computationally expensive and time consuming. While on other hand, the heat conduction model can accurately simulate the melt pool evolution with a factor $C_{m}$ applied to mimic the Marangoni effect on the melt pool. But due the uncertainty in selecting the correction factor (as evidenced by the wide range of values proposed in literature), there remains a key question about the appropriate values of $C_{m}-$ it requires a significant trial-and-error process to define acceptable values. Therefore, to bridge this gap, the current study is focused on developing a method to correlate the correction factor and the surface tension gradients that cause the Marangoni phenomenon within the melt pool of a moving heat source.

This study is been carried out by undertaking verification steps [30] for grid evaluation and then making code-to-code comparisons. Here, the individual simulation applications for the moving heat source were developed in ANSYS Fluent CFD software and using a heat conduction model prepared in Ansys Parametric Design Language (APDL). Mesh independent results of thermal analysis and melt pool dimensions were obtained for each code. Using the value of peak temperatures as a guide the correlation between surface tension and correction factor is proposed. This correlation will be useful to those modellers wishing to develop realistic results using a reduced-physics heat conduction model for simulating moving heat sources.

\subsection{Aim and objectives}

The aim of the present work is to investigate the hypothesis (commonly used in simulation of melt pool formation under a moving point heat source) that a correction factor used to modify the liquid thermal conductivity in a heat-conduction model replicates the effects of Marangoni convection within the melt pool. Furthermore, the work will investigate whether it is possible to correlate different levels of correction factor in a conduction model to different 
levels of surface tension gradient within a CFD model that includes Marangoni convection. Objectives of the present study are as follows:

(1) To develop two independent thermal models of melt pool formation under a moving point heat source on a metal alloy substrate: one using a CFD model that includes Marangoni convection and the other using heat conduction combined with latent heat effects.

(2) Study the effects of Marangoni convection for different levels of surface tension gradient on temperature distribution (thermal profile, peak temperature, etc.) and melt pool geometry using the CFD model.

(3) Investigate the effects of a correction factor applied to a reduced-physics thermal model based on conduction and latent heat generation only.

(4) Investigate if there is a correlation between the surface tension parameter in a CFD model and the correction factor for a reduced-physics heat conduction model.

The manuscript is divided into Methodology, Results, Discussion, and Conclusion sections. The Methodology section describes the governing equations, boundary conditions and simulation setups used for the CFD and heat conduction models. The Results section describes the thermal histories, thermal profile, peak temperatures, and melt pool dimensions obtained for each code. The discussion section proposes a correlation between correction factor and surface tension gradient. Finally, the conclusion section summarizes the significant outcomes of the present study.

\section{Methodology}

\subsection{Governing equations}

The governing equations for the CFD model are solved using a Finite Volume Method $(\mathrm{FVM})$ in Fluent and for the heat conduction model the equations are solved using the Finite Element Method (FEM) using an APDL code. 


\subsubsection{CFD model}

In the present study the flow within the melt pool is assumed to be laminar. The equations for mass, momentum and energy governing equations are solved by enabling the energy and solidification and melting models. The governing equations are provided.

Mass or continuity conservation equation is as follow:

$$
\frac{\partial \rho}{\partial t}+\nabla \cdot(\rho \vec{V})=0
$$

Where, $\rho$ is the temperature dependent value of density, $t$ is the time, and $\vec{V}$ is the fluid flow velocity.

Momentum conservation equation is as follow:

$$
\frac{\partial(\rho \vec{V})}{\partial t}+\nabla \cdot(\rho \vec{V} \vec{V})=-\nabla p+\rho \vec{g}+\vec{F}
$$

Where, $p$ is the static pressure, $\rho \vec{g}$ is the gravitational body force and $\vec{F}$ is the external body force.

The Boussinesq approximation is used to calculate the buoyancy force in the melt pool using following equation:

$$
g\left(\rho-\rho_{0}\right) \approx-\rho_{0} \beta\left(T-T_{0}\right) g
$$

Where, $g$ is gravitational acceleration; $\rho_{0}$ is operating or reference density; $\beta$ is the coefficient of volumetric expansion and $T_{0}$ is operating or reference temperature.

The energy conservation equation is as follow:

$$
\frac{\partial(\rho H)}{\partial t}+\nabla \cdot(\vec{V} \rho h)=\nabla \cdot(K \nabla T)
$$

Where, $T$ is the temperature, $t$ is the time, $\rho$ and $H$ are the temperature dependent values of density and enthalpy of Ti-6Al-4V material, respectively.

In the CFD model, the effect of latent heat is given by computing the enthalpy of the material ' $H$ ' as the sum of sensible enthalpy ' $h$ ' and specific enthalpy of latent heat ' $\Delta H$ '. 


$$
H=h+\Delta H
$$

The specific enthalpy of latent heat ' $\Delta H$ ' is the product of the liquid fraction $f_{L}$ and volumetric latent heat of fusion $L$.

$$
\Delta H=f_{L} L
$$

The liquid fraction is defined as follow:

$$
f_{L}=\left\{\begin{array}{cl}
0 & \text { if } T \leq T_{S} \\
\frac{T-T_{S}}{T_{L}-T_{S}} & \text { if } T_{S}<T<T_{L} \\
1 & \text { if } T \geq T_{L}
\end{array}\right.
$$

The liquidus temperature and solidus temperatures are given by $T_{L}$ and $T_{S}$, respectively.

\subsubsection{Heat conduction model}

In the heat conduction model, the governing equation is be expressed as:

$$
\frac{\partial H}{\partial t}=\nabla \cdot[K \nabla T]
$$

Where, $T$ is the temperature; $t$ is the time; $H$ and $K$ are the temperature dependent values of enthalpy, and thermal conductivity of Ti-6Al-4V material, respectively.

In the heat conduction model, the effect of phase change has been given by modifying the specific heat capacity and calculating the enthalpy of solid $H_{s}$, mush, $H_{m}$, and liquid, $H_{l}$, as follows:

$$
\begin{aligned}
& H_{S}(T)=\rho C_{S}\left(T-T_{0}\right) \\
& H_{m}(T)=H_{S}\left(T_{S}\right)+\rho C^{*}\left(T-T_{S}\right) \\
& C^{*}=\left(\frac{C_{S}+C_{L}}{2}\right)+\left(\frac{L}{T_{L}-T_{S}}\right) \\
& H_{l}(T)=H_{m}\left(T_{L}\right)+\rho C_{L}\left(T-T_{L}\right)
\end{aligned}
$$

Where, $\rho$ is the density of material, $C_{s}, C^{*}$, and $C_{L}$ are the specific heat capacities of the material as solid, mush and liquid, respectively; $L$ is the latent heat of fusion; $T_{0}, T_{S}$, and $T_{L}$ are the ambient, solidus, and liquidus temperature, respectively. 


\subsection{Initial condition}

At the simulation start time (i.e. at $\mathrm{t}=0 \mathrm{~s}$ ) the initial temperature of the substrate material, $T_{i}$, is at ambient temperature, $T_{o}$, of $298.15 \mathrm{~K}$.

$$
T(x, y, z, t)=T_{i}=T_{0}=298.15 \mathrm{~K} \text { at } t=0 \mathrm{~s}
$$

\subsection{Boundary conditions}

The following points describe details of the boundary conditions used in both the CFD and heat conduction models.

- Heat source model: The input heat flux included in the form of a 2D Gaussian heat source model has been as expressed as:

$$
q=\frac{2 A P}{\pi R^{2}} \exp \left(\frac{-2\left(x^{2}+y^{2}\right)}{R^{2}}\right)
$$

where, $A$ is absorptivity of the heat source power by the substrate material; $P$ is the power of heat source; $R$ is the spot size radius of the heat source; $x$ and $y$ are the local coordinates of the point of irradiation in a Cartesian coordinate system on the heat in out surface.

- Convection and radiation boundary conditions: The heat loss due to convection and radiation from the external boundaries of the substrate material has been represented using the following equations:

$$
\begin{aligned}
& q_{c}=h_{c}\left(T-T_{0}\right) \\
& q_{r}=\varepsilon \sigma\left(T^{4}-T_{0}^{4}\right)
\end{aligned}
$$

Where, $q_{c}$ and $q_{r}$ are heat flux terms due to convection and radiation; $h_{c}$ is the convective heat transfer coefficient; $\varepsilon$ is the emissivity coefficient; and $\sigma$ is Stefan-Boltzmann constant.

\subsection{Marangoni effect}

In the CFD model, the effect of Marangoni convection has been given in the momentum equation. Here, the value of surface tension gradient, $\frac{\partial \gamma}{\partial T}$, is used to calculate the Marangoni shear stress ' $\tau$ ' as described in below equation: 


$$
\tau=\frac{\partial \gamma}{\partial T} \nabla_{s} T
$$

Where, $\nabla_{\mathrm{S}}$ is the surface gradient.

In heat conduction model, the effect of Marangoni phenomena is considered by modifying the temperature dependent value of thermal conductivity $K^{*}(T)$ above liquidus temperature $T_{L}$. This modification is represented in the form of correction factor $C_{m}$.

$$
K^{*}(T)=C_{m} K(T) \text { if } T>T_{L}
$$

\subsection{Simulation setup}

Figure 1 depicts the schematic of the 3D geometry (Fig. 1(a)) and meshed domain (Fig. 1(b)) of the substrate material. The 3D model geometry of $3 \mathrm{~mm}$ by $1 \mathrm{~mm}$ by $0.25 \mathrm{~mm}$ was used in both the CFD model and heat conduction model. The movement of the heat source along the travel length of $2 \mathrm{~mm}$ has been coded with User Defined Functions (UDF's) in the CFD model and using parametric design language in the heat conduction model. Figure 1(b) also shows the 3D geometry with meshing. The geometry of the substrate material has been discretised uniformly with a brick mesh of $10 \mu \mathrm{m}$ size in all directions. To obtain mesh independent results, the mesh sensitivity analysis exercise was carried out for both CFD and heat conduction models. The following procedure was implemented. Initially, the domain was discretised with a coarse mesh size of $25 \mu \mathrm{m}$. Thereafter, the mesh size was sequentially reduced to $20 \mu \mathrm{m}, 15 \mu \mathrm{m}$, and $10 \mu \mathrm{m}$. The temperature distribution remained unaffected after implementing the mesh size of $10 \mu \mathrm{m}$; therefore, this mesh size was selected for domain in both the CFD and heat conduction models.

[Figure 1 near here]

Figure 2 depicts the thermophysical material properties such as thermal conductivity (Fig. 2(a)), specific heat capacity (Fig. 2(b)) and density (Fig. 2(c)) for Ti-6Al-4V, which was the material considered in the present study [31]. In addition to the thermophysical material 
properties, other properties of Ti-6Al-4V were required for the CFD model. All process parameters used in current study are summarized in Table 1.

[Figure 2 near here]

[Table 1 near here]

\section{Results}

The results of temperature distribution, thermal histories, thermal profile, and melt pool dimensions obtained for both the CFD and heat conduction models are described as follow.

\subsection{Temperature distribution}

In the CFD model, the effect of Marangoni convection depends on the value of surface tension gradient. Different values of surface tension gradient for Ti-6Al-4V are cited in literature, such as $-0.26 \times 10^{-3} \mathrm{~N} / \mathrm{m} \cdot \mathrm{K}[22]$ and $-0.37 \times 10^{-3} \mathrm{~N} / \mathrm{m} \cdot \mathrm{K}[32]$. Hence, in this study, results with three input values of surface tension gradient were simulated initially, namely, with $\frac{\partial \gamma}{\partial T}$ set to $0 \mathrm{~N} / \mathrm{m} \cdot \mathrm{K},-0.26 \times 10^{-3} \mathrm{~N} / \mathrm{m} \cdot \mathrm{K}$, and $-0.37 \times 10^{-3} \mathrm{~N} / \mathrm{m} \cdot \mathrm{K}$. Figure 3 shows the temperature distributions for the moving heat source simulations when it is at the mid-point (i.e. $\mathrm{X}=1.5 \mathrm{~mm}$ ) of the travel length. Figure $3(\mathrm{a})$ was generated with $\frac{\partial \gamma}{\partial T}$ set to $0 \mathrm{~N} / \mathrm{m} \cdot \mathrm{K}$ (that is, with no Marangoni effect); Figure 3(b) with $\frac{\partial \gamma}{\partial T}$ set to $-0.26 \times 10^{-3} \mathrm{~N} / \mathrm{m} \cdot \mathrm{K}$; and Figure 3(c) with $\frac{\partial \gamma}{\partial T}$ set to $-0.37 \times 10^{-3} \mathrm{~N} / \mathrm{m} \cdot \mathrm{K}$.

In the heat conduction model, the value of thermal conductivity of liquid was modified proportionally with various correction factor, $C_{m}$. Figure 4 depicts he distribution of temperature captured in heat conduction model for different values of correction factor. Figure 4(a) shows the result with $C_{m}=1$ (that is with no correction effect); Figure 4(b) with $C_{m}=1.65$; Figure 4(c) with $C_{m}=2.0$; and Figure 4(d) with $C_{m}=2.5$.

[Figure 3 near here]

[Figure 4 near here] 


\subsection{Thermal histories}

Figure 5 and 6 depicts the thermal histories captured at the starting point (i.e. $\mathrm{X}=0.5$ $\mathrm{mm}$ ), mid-point (i.e. $X=1.5 \mathrm{~mm})$ and end-point $(X=2.5 \mathrm{~mm})$ of the moving heat source for the CFD and heat conduction models, respectively. These figures show the change in the temperature with respect to time and demonstrate the heating and cooling cycle experienced at several positions along the centreline of the substrate, directly on the travel path of the moving heat source. The thermal histories captured in the CFD model (Figure 5) were calculated with increasing values of surface tension gradient. While similar results were simulated in the heat conduction model (Figure 6) with increasing values of correction factor. The values for $\frac{\partial \gamma}{\partial T}$ and $C_{m}$ used the same as reported previously in section 3.1 (and were used throughout to generate all these initial results).

[Figure 5 near here]

[Figure 6 near here]

\subsection{Thermal profile}

Figure 7 and 8 illustrate the results for the thermal profiles captured for different values of surface tension gradient in the CFD model and correction factor in the heat conduction model, respectively. The results were taken along the line of travel of the heat source at various times: $0.01 \mathrm{~ms}, 1.0 \mathrm{~ms}$, and $2.0 \mathrm{~ms}$. Additionally, the thermal profiles were also captured at a time of $2.5 \mathrm{~ms}$ after the heat source was turned off and the substrate had cooled naturally.

[Figure 7 near here]

[Figure 8 near here]

\subsection{Peak temperatures and melt pool dimensions}

Tables 2 and 3 shows the data for the peak temperature and melt pool dimensions acquired for different value of surface tension gradient in the CFD model and a corresponding 
correction factor in the heat conduction model. The values of the surface tension gradient and correction factor were selected in such way that the percentage difference between the peak temperatures should be less than 5\%. The peak temperatures, melt pool width, depth and length values were recorded when the heat source is at the mid-point of the travel length (i.e. $\mathrm{X}=1.5 \mathrm{~mm}$ ) at time as $1.0 \mathrm{~ms}$.

[Table 2 near here]

[Table 3 near here]

\section{Discussion}

\subsection{Peclet and Marangoni numbers}

The Peclet number is used to relate the transport of energy due to advection and conduction within the substrate. Qualitatively when the Peclet number is greater than 1, advection has the greater influence on the thermal energy transportation [34]. In past literature, two equations are used to calculate the Peclet number $[32,35]$. In present study, the Peclet number is calculated using.

$$
P_{e}=\frac{V d_{h s}}{\alpha}
$$

Where, $P_{e}$ is the Peclet number, $V$ is the scanning speed of heat source $(\mathrm{m} / \mathrm{s}), d_{h s}$ is the diameter of heat source $(\mathrm{m})$ and $\alpha$ is the thermal diffusivity of Ti-6Al-4V at $298.15 \mathrm{~K}$. In the case studied here the Peclet number was $P_{e}=19.3$. This relatively higher value of Peclet number indicates that the advection rate is in an order of magnitude higher than the heat conduction within the substrate. This value of Peclet number is representative of the Laserbased, Powder Bed Fusion AM process.

Marangoni number is used to relate the surface tension force with the viscous force within the melt pool. The Marangoni number is calculated using.

$$
M_{n}=-\frac{\partial \gamma}{\partial T} \frac{w \Delta T}{\mu \alpha}
$$


Where, $M_{n}$ is the Marangoni number, $w$ is the width of the melt pool, $\mu$ is the viscosity of Ti$6 \mathrm{Al}-4 \mathrm{~V}$, and $\Delta T$ is the difference between the peak temperature of melt pool and solidus temperature of the Ti-6AL-4V material.

The Marangoni number calculated for the Surface tension gradient of Ti-6Al-4V 4V (i.e. $\left.\partial \gamma / \partial \mathrm{T}=-0.37 \times 10^{-3} \mathrm{~N} / \mathrm{m} \cdot \mathrm{K}\right)$ was $M_{n}=13,064$. In the study proposed by Mukherjee et al. [32] for the laser based additive manufacturing process, the higher value of Marangoni number indicates that the convective heat transfer is mainly driven by surface tension gradient. Therefore, the high Marangoni number in the present study reinforces the view that the parameters used are typical for laser-based Powder Bed Fusion AM processes in metals.

\subsection{Thermal Analysis Discussion}

For the CFD model results, Figure 3 revealed that increasing the value of surface tension gradient had the effect of reducing the temperature gradient and widening the heat affected zone around the heat source. The thermal histories captured (Figure 5) showed that for by increasing value of surface tension gradient, the peak temperatures decreased significantly. The thermal profile (Figure 7) captured along the centreline of the travel path position revealed that, for the increasing value of surface tension gradient, the influence of phase transition at the tail of the heat source reduced. Therefore, the analysis from CFD model signifies that the thermal distribution is significantly dependent on by the surface tension gradient value of Ti-6Al-4V.

For heat conduction, the increased values of correction factor had minimal influence on the width and depth of the melt pool. However, the length of the melt pool did reduce which was similar in effect to increasing the surface tension gradient. Thermal histories plots (Figure 6) revealed that by increasing the value of correction factor, the peak temperature within melt pool decreased. Thermal profiles (Figure 8) showed that by increasing the value of correction factor, the length of the tail of the melt pool decreased. Therefore, the analysis 
from the heat conduction model revealed that the thermal distribution in the melt pool was influenced (in a similar nature to modifying surface tension gradient) by modifying the liquid thermal conductivity by a factor of $C_{m}$.

\subsection{Correlation between Correction Factor and Surface Tension Gradient}

The data for Table 2 was generated by trial and error on the basis that the peak temperatures values obtained for the correction factors should be within $5 \%$ of the corresponding peak temperature of surface tension gradient. This allowed a correlation to be established as shown in Figure 9.

A non-linear trend is proposed, which follows:

$$
C_{m}=1+a\left(-\frac{\partial \gamma}{\partial T}\right)^{b}
$$

Using a regression technique of linearizing through the application of logarithms and then finding the line of best fit, the parameters for equation (21) are provided in Table 4.

[Table 4 near here]

[Figure 9 near here]

From Figure 9, it can be observed that when there is no Marangoni effect is considered in

CFD modelling (i.e. $\frac{\partial \gamma}{\partial T}=0$ ), the $C_{m}$ is set to unity for the heat conduction model. While for the quoted value of the surface tension gradient of Ti-6Al-4V (i.e. $\partial \gamma / \partial \mathrm{T}=-0.37 \times 10^{-3}$ $\mathrm{N} / \mathrm{m} \cdot \mathrm{K})$ the corresponding correction factor is approximately equal to two $\left(C_{m}=2\right)$ for the heat conduction model. This value is close to the suggested correction factor proposed by Lampa et al. [17] of 2.5. The predicted $C_{m}$ by the regression equation (21) is 1.76 . The peak temperature computed using this value in the heat conduction model is $5154.58 \mathrm{~K}$. The percentage difference between the peak temperatures computed by the predicted $C_{m}$ of 1.76 and with a surface tension gradient of Ti-6Al-4V (i.e. $\partial \gamma / \partial \mathrm{T}=-0.37 \times 10-3 \mathrm{~N} / \mathrm{m} \cdot \mathrm{K}$ ) is $2.56 \%$. 
Therefore, the regression equation proposed in the present study has ability to predict $C_{m}$ for the corresponding surface tension gradient of Ti-6Al-4V with good agreement.

In Table 3, the melt pool dimensions for the corresponding cases in Table 2 are provided. At the initial case (Case No. 1) the dimension of the melt pool for the CFD and heat

conduction models are in close agreement. This is because the values of $C_{m}$ and $\frac{\partial \gamma}{\partial T}$ in the first case has no Marangoni convection and hence no fluid flow is involved. Therefore, the heat transfer in first case is mainly influenced by the conduction in both the models. For increasing values of $\frac{\partial \gamma}{\partial T}$ in the CFD model, the depth and length of the melt pool were reduced. On the other hand, the width of the melt pool increased slightly from 0.11 to 0.13 as the surface tension gradient increased.

In the heat conduction model with increasing levels of $C_{m}$ the width and depth remain unaffected, but length decreased. In all cases of the heat conduction model, the predicted width was smaller than for the case with fluid flow. A similar phenomenon has been reported by Jamshidinia et al. [23] when Marangoni convection was ignored.

\section{Conclusion}

This paper investigated the correlation between the surface tension gradient and correction factor to incorporate the effects Marangoni convection in the melt pool formed by the moving point heat source. The following conclusions have been drawn:

1. The developed CFD model and the reduced-physics heat conduction model can simulate the melt pool formation for the moving heat source.

2. In the CFD model, the negative value of surface tension gradient created an outward flow of liquid within the melt pool due to surface driven Marangoni convection. The increasing in absolute values of surface tension (i.e., more negative values), increases the convective transport thereby influencing the temperature distribution within the 
melt pool and, consequently, caused increases in the melt pool width and decreases in the melt pool depth and length.

3. The correction factor used to incorporate Marangoni effect in the heat conduction model revealed that the increasing value of the liquid thermal conductivity also influenced the temperature distribution within the melt pool. The width and depth of melt pool remained unaffected while the length of melt pool decreased.

4. The correlation between the surface tension gradient and the correction factor was approximated as $C_{m}=1+a(-\partial \gamma / \partial T)^{b}$ where $a=282.4268$ and $b=0.7485$.

5. The correlation study revealed that for the most realistic value of surface tension gradient i.e. $-0.37 \times 10^{-3} \mathrm{~N} / \mathrm{m} \cdot \mathrm{K}$ of Ti- $6 \mathrm{Al}-4 \mathrm{~V}$ the corresponding correction factor is approximately equal to 1.76 .

It was shown that throughout the literature, different values of correction factors have been applied to heat conduction models in order to replicate the thermal effects of Marangoni convection with no general agreement. The results demonstrated in this manuscript is a specific study on a Ti-6AL-4V under a specific set of processing parameters (typical of Laser-based Powder Bed Fusion). The procedure focussed on the finding similarity in the peak temperatures as the main comparison criterion. The generality of the correction factor found here and its applicability to other processes and materials would need to be investigated further; however, the procedure could be applied generally in those investigations. It would be interesting to investigate the correlations of $C_{m}$ to surface tension gradient for other materials systems and to investigate the similitude by focussing on dimensionless numbers (Peclet number, dimensionless power, etc.).

Overall, once applied to a specific material and process, the correlation should be reusable for processes under the same conditions. The method of correlation outlined in this study will 
reduce the trial-and-error simulation runs required in reduced-physics heat conduction modelling - a result that will be useful to the wider community.

\section{Disclosure statement}

The authors have no conflict of interest to declare.

\section{Funding Acknowledgement}

This work was conducted as part of the North West Centre for Advanced Manufacturing (NW CAM) project, which is supported by the European Union's INTERREG VA Programme, managed by the Special EU Programmes Body (SEUPB).

The views and opinions in this document do not necessarily reflect those of the European Commission or the Special EU Programmes Body (SEUPB). For further information about NW CAM please contact the lead partner, Catalyst, in Northern Ireland for details.

\section{References}

[1] L. Aucott et al., "Revealing internal flow behaviour in arc welding and additive manufacturing of metals," Nat. Commun., vol. 9, no. 1, pp. 1-7, 2018, DOI: 10.1038/s41467-018-07900-9.

[2] S. Wang, R. Nates, T. Pasang, and M. Ramezani, "Modelling of Gas Tungsten Arc Welding Pool under Marangoni Convection," Univers. J. Mech. Eng., vol. 3, no. 5, pp. 185-201, 2015, DOI: 10.13189/ujme.2015.030504.

[3] P. G. Jönsson, R. C. Westhoff, and J. Szekely, "Arc characteristics in gas-metal arc welding of aluminum using argon as the shielding gas," J. Appl. Phys., vol. 74, no. 10, pp. 5997-6006, 1993, DOI: 10.1063/1.355213.

[4] Y. Wang and H. L. Tsai, "Effects of surface active elements on weld pool fluid flow and weld penetration in gas metal arc welding," Metall. Mater. Trans. B, vol. 32, no. 3, pp. 501-515, 2001, DOI: 10.1007/s11663-001-0035-5. 
[5] Y. Wang, Q. Shi, and H. L. Tsai, "Modeling of the effects of surface-active elements on flow patterns and weld penetration," Metall. Mater. Trans. B, vol. 32, no. 1, pp. 145161, 2001, DOI: 10.1007/s11663-001-0017-7.

[6] T. Zacharia, S. A. David, J. M. Vitek, and H. G. Kraus, "Computational modeling of stationary gas tungsten-arc weld pools and comparison to stainless steel 304 experimental results," Metall. Trans. B, vol. 22, no. 2, pp. 243-257, 1991, DOI: 10.1007/BF02652489.

[7] M. Tong et al., "Multiscale, multiphysics numerical modeling of fusion welding with experimental characterization and validation," JOM, vol. 65, no. 1, pp. 99-106, 2013, DOI: $10.1007 / \mathrm{s} 11837-012-0499-6$.

[8] V. Manvatkar, A. De, and T. DebRoy, "Spatial variation of melt pool geometry, peak temperature and solidification parameters during laser assisted additive manufacturing process," Mater. Sci. Technol., vol. 31, no. 8, pp. 924-930, 2015, DOI: 10.1179/1743284714Y.0000000701.

[9] J. I. Arrizubieta, A. Lamikiz, F. Klocke, S. Martínez, K. Arntz, and E. Ukar, "Evaluation of the relevance of melt pool dynamics in Laser Material Deposition process modeling," Int. J. Heat Mass Transfer, vol. 115, pp. 80-91, 2017, DOI: 10.1016/j.ijheatmasstransfer.2017.07.011.

[10] C. Panwisawas et al., "Mesoscale modelling of selective laser melting: Thermal fluid dynamics and microstructural evolution," Comput. Mater. Sci., vol. 126, pp. 479-490, 2017, DOI: 10.1016/j.commatsci.2016.10.011.

[11] J. C. Haley, J. M. Schoenung, and E. J. Lavernia, "Modelling particle impact on the melt pool and wettability effects in laser directed energy deposition additive manufacturing," Mater. Sci. Eng. A, vol. 761, pp. 138052(1-10), 2019, DOI: 10.1016/j.msea.2019.138052. 
[12] Y. S. Lee and W. Zhang, "Mesoscopic Simulation of Heat Transfer and Fluid Flow in Laser Powder Bed Additive Manufacturing," In: 26th Annual International Solid Freeform Fabrication Symposium - An Additive Manufacturing Conference, 2015, pp. $1154-1165$.

[13] S. H. Nikam and N. K. Jain, "3D-finite element simulation and image processing based prediction of width and height of single-layer deposition by micro-plasma-transferred arc process," Int. J. Adv. Manuf. Technol., vol. 95, no. 9-12, pp. 3679-3691, 2018, DOI: 10.1007/s00170-017-1472-x.

[14] T. Amine, J. W. Newkirk, and F. Liou, "Investigation of effect of process parameters on multilayer builds by direct metal deposition," Appl. Therm. Eng., vol. 73, no. 1, pp. 500511, 2014, DOI: 10.1016/j.applthermaleng.2014.08.005.

[15] A. Kumar, C. P. Paul, A. K. Pathak, P. Bhargava, and L. M. Kukreja, “A finer modeling approach for numerically predicting single track geometry in two dimensions during Laser Rapid Manufacturing,” Opt. Laser Technol., vol. 44, no. 3, pp. 555-565, 2012, DOI: 10.1016/j.optlastec.2011.08.026.

[16]E. Kundakcioglu, I. Lazoglu, and S. Rawal, "Transient thermal modeling of laser-based additive manufacturing for 3D freeform structures," Int. J. Adv. Manuf. Technol., vol. 85, no. $1-4$, pp. 493-501, 2016, DOI: 10.1007/s00170-015-7932-2.

[17] C. Lampa, A. F. H. Kaplan, J. Powell, and C. Magnusson, "An analytical thermodynamic model of laser welding," J. Phys. D: Appl. Phys., vol. 30, no. 9, pp. 1293-1299, 1997, DOI: 10.1088/0022-3727/30/9/004.

[18]B. Xiao and Y. Zhang, "Marangoni and Buoyancy effects on direct metal laser sintering with a moving laser beam," Numer. Heat Transfer, Part A, vol. 51, no. 8, pp. 715-733, 2007, DOI: 10.1080/10407780600968593. 
[19] S. A. Khairallah, A. T. Anderson, A. Rubenchik, and W. E. King, "Laser powder-bed fusion additive manufacturing: Physics of complex melt flow and formation mechanisms of pores, spatter, and denudation zones," Acta Mater., vol. 108, pp. 36-45, 2016, DOI: 10.1016/j.actamat.2016.02.014.

[20] M. Xia, D. Gu, G. Yu, D. Dai, H. Chen, and Q. Shi, "Porosity evolution and its thermodynamic mechanism of randomly packed powder-bed during selective laser melting of Inconel 718 alloy," Int. J. Mach. Tools Manuf., vol. 116, pp. 96-106, 2017, DOI: 10.1016/j.ijmachtools.2017.01.005.

[21]T. Heeling, M. Cloots, and K. Wegener, "Melt pool simulation for the evaluation of process parameters in selective laser melting," Addit. Manuf., vol. 14, pp. 116-125, 2017, DOI: 10.1016/j.addma.2017.02.003.

[22] S. Shrestha, B. Cheng, and K. Chou, "An investigation into melt pool effective thermal conductivity for thermal modeling of powder-bed electron beam additive manufacturing," In: 27th Annual International Solid Freeform Fabrication Symposium An Additive Manufacturing Conference, 2016, pp. 207-218.

[23] M. Jamshidinia, F. Kong, and R. Kovacevic, "Numerical modeling of heat distribution in the electron beam melting® of Ti-6Al-4V," J. Manuf. Sci. Eng., vol. 135, no. 6, pp. 061010-1-061010-14, 2013, DOI: 10.1115/1.4025746.

[24] A. Kidess, S. Kenjereš, B. W. Righolt, and C. R. Kleijn, "Marangoni driven turbulence in high energy surface melting processes," Int. J. Therm. Sci., vol. 104, pp. 412-422, 2016, DOI: 10.1016/j.ijthermalsci.2016.01.015.

[25] S. Kumar, S. Roy, C. P. Paul, and A. K. Nath, "Three-dimensional conduction heat transfer model for laser cladding process," Numer. Heat Transfer, Part B, vol. 53, no. 3, pp. 271-287, 2008, DOI: 10.1080/10580530701790159. 
[26] A. Kumar, C. P. Paul, A. S. Padiyar, P. Bhargava, G. Mundra, and L. M. Kukreja, "Numerical simulation of laser rapid manufacturing of multi-layer thin wall using an improved mass addition approach," Numer. Heat Transfer, Part A, vol. 65, no. 9, pp. 885-910, 2014, DOI: 10.1080/10407782.2013.850968.

[27] S. H. Nikam and N. K. Jain, "Three-dimensional thermal analysis of multi-layer metallic deposition by micro-plasma transferred arc process using finite element simulation," J. Mater. Process. Technol., vol. 249, pp. 264-273, 2017, DOI: 10.1016/j.jmatprotec.2017.05.043.

[28]A. De and T. DebRoy, "Improving reliability of heat and fluid flow calculation during conduction mode laser spot welding by multivariable optimisation," Sci. Technol. Weld. Joining, vol. 11, no. 2, pp. 143-153, 2006, DOI: 10.1179/174329306X84346.

[29] J. Romano, L. Ladani, and M. Sadowski, "Laser Additive Melting and Solidification of Inconel 718: Finite Element Simulation and Experiment,” JOM, vol. 68, no. 3, pp. 967977, 2016, DOI: 10.1007/s11837-015-1765-1.

[30] P. J. Roache, "Verification of codes and calculations," AIAA Journal, vol. 36, no. 5, pp. 696-702, 1998, DOI: 10.2514/2.457.

[31] K. C. Mills, Recommended values of thermophysical properties for selected commercial alloys. Abington, Cambridge, England, Woodhead Publishing Limited, 2011.

[32] T. Mukherjee, V. Manvatkar, A. De, and T. DebRoy, "Dimensionless numbers in additive manufacturing," J. Appl. Phys., vol. 121, no. 6, pp. 064904-1-064904-10, 2017, DOI: $10.1063 / 1.4976006$.

[33] W. Huang and Y. Zhang, "Finite element simulation of thermal behavior in single-track multiple-layers thin wall without-support during selective laser melting," J. Manuf. Process., vol. 42, no. October 2018, pp. 139-148, 2019, DOI: 10.1016/j.jmapro.2019.04.019. 
[34]Q. Guo et al., "In-situ full-field mapping of melt flow dynamics in laser metal additive manufacturing," Addit. Manuf., vol. 31, no. July 2019, pp. 100939(1-10), 2020, DOI: 10.1016/j.addma.2019.100939.

[35] M. van Elsen, F. Al- Bender, and J. Kruth, "Application of dimensional analysis to selective laser melting," Rapid Prototyp. J., vol. 14, no. 1, pp. 15-22, 2008, DOI: $10.1108 / 13552540810841526$. 
Tables with caption

Table 1. Values of other properties of Ti-6Al-4V and process parameters used for simulation.

\section{Other properties and process parameters Symbols Values (Units)}

\begin{tabular}{|c|c|c|}
\hline Viscosity & $\mu$ & $0.004(\mathrm{Kg} / \mathrm{m} \cdot \mathrm{s})[32]$ \\
\hline Thermal expansion coefficient & $\beta$ & $2.5 \times 10^{-5}(1 / \mathrm{K})[32]$ \\
\hline Latent heat of fusion & $L$ & $365000(\mathrm{~J} / \mathrm{Kg})[33]$ \\
\hline Solidus temperature & $T_{S}$ & $1873.15(\mathrm{~K})$ \\
\hline Liquidus temperature & $T_{L}$ & $1923.15(\mathrm{~K})$ \\
\hline Convective heat transfer coefficient & $h_{c}$ & $160\left(\mathrm{~W} / \mathrm{m}^{2} \cdot \mathrm{K}\right)$ \\
\hline Emissivity coefficient & $\varepsilon$ & 0.7 \\
\hline Stefan-Boltzmann constant & $\sigma$ & $5.67 \times 10^{-8}\left(\mathrm{~W} / \mathrm{m}^{2} \cdot \mathrm{K}^{4}\right)$ \\
\hline Absorption coefficient & $A$ & 0.55 \\
\hline Power of heat source & $P$ & $95(\mathrm{~W})$ \\
\hline Scanning speed of heat source & $V$ & $1000(\mathrm{~mm} / \mathrm{sec})$ \\
\hline Spot radius of heat source & $R$ & $0.05(\mathrm{~mm})$ \\
\hline
\end{tabular}


Table 2. Peak temperatures values obtained by different values of surface tension gradient in CFD model and correction factor in heat conduction model.

\begin{tabular}{|c|c|c|c|c|}
\hline \multirow[t]{2}{*}{ Case No. } & \multicolumn{2}{|c|}{ CFD model } & \multicolumn{2}{|c|}{ Heat conduction model } \\
\hline & 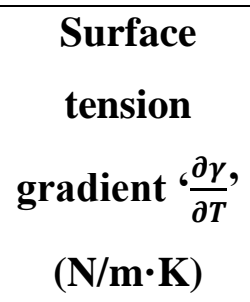 & $\begin{array}{c}\text { Peak temperatures } \\
\text { (K) }\end{array}$ & $\begin{array}{l}\text { Correction } \\
\text { factor ' } C_{m} \text { ', }\end{array}$ & $\begin{array}{c}\text { Peak } \\
\text { temperatures } \\
(\mathrm{K})\end{array}$ \\
\hline 1 & 0 & 7270.17 & 1.00 & 7292.14 \\
\hline 2 & $-0.397 \times 10^{-4}$ & 7010.95 & 1.10 & 6943.55 \\
\hline 3 & $-0.790 \times 10^{-4}$ & 6481.39 & 1.27 & 6458.89 \\
\hline 4 & $-0.130 \times 10^{-3}$ & 6048.64 & 1.44 & 5959.33 \\
\hline 5 & $-0.260 \times 10^{-3}$ & 5440.52 & 1.65 & 5559.64 \\
\hline 6 & $-0.370 \times 10^{-3}$ & 5176.86 & 2.00 & 5025.62 \\
\hline 7 & $-0.6 \times 10^{-3}$ & 4886.64 & 2.03 & 4815.06 \\
\hline 8 & $-0.8 \times 10^{-3}$ & 4731.73 & 2.23 & 4611.46 \\
\hline 9 & $-0.120 \times 10^{-2}$ & 4522.23 & 2.50 & 4491.58 \\
\hline
\end{tabular}


Table 3. Melt pool dimensions obtained in CFD and heat conduction model.

\begin{tabular}{ccccccc}
\hline Case No. & \multicolumn{3}{c}{ CFD model } & \multicolumn{3}{c}{ Heat conduction model } \\
\cline { 2 - 7 } & $\begin{array}{c}\text { Width } \\
(\mathbf{m m})\end{array}$ & $\begin{array}{c}\text { Depth } \\
(\mathbf{m m})\end{array}$ & $\begin{array}{c}\text { Length } \\
(\mathbf{m m})\end{array}$ & $\begin{array}{c}\text { Width } \\
(\mathbf{m m})\end{array}$ & $\begin{array}{c}\text { Depth } \\
(\mathbf{m m})\end{array}$ & $\begin{array}{c}\text { Length } \\
(\mathbf{m m})\end{array}$ \\
\hline 1 & 0.11 & 0.030 & 0.300 & 0.10 & 0.030 & 0.28 \\
\hline 2 & 0.11 & 0.028 & 0.290 & 0.10 & 0.030 & 0.25 \\
\hline 3 & 0.11 & 0.024 & 0.270 & 0.10 & 0.030 & 0.24 \\
\hline 4 & 0.11 & 0.020 & 0.250 & 0.10 & 0.030 & 0.23 \\
\hline 5 & 0.12 & 0.018 & 0.238 & 0.10 & 0.030 & 0.22 \\
\hline 6 & 0.12 & 0.017 & 0.232 & 0.10 & 0.030 & 0.21 \\
\hline 7 & 0.12 & 0.016 & 0.231 & 0.10 & 0.030 & 0.21 \\
\hline 8 & 0.12 & 0.014 & 0.229 & 0.10 & 0.030 & 0.20 \\
\hline & & & & & & \\
\hline
\end{tabular}


Table 4. Correlation equation coefficients.

a 282.4268

$\begin{array}{ll}b & 0.7485\end{array}$ 
Figures with caption

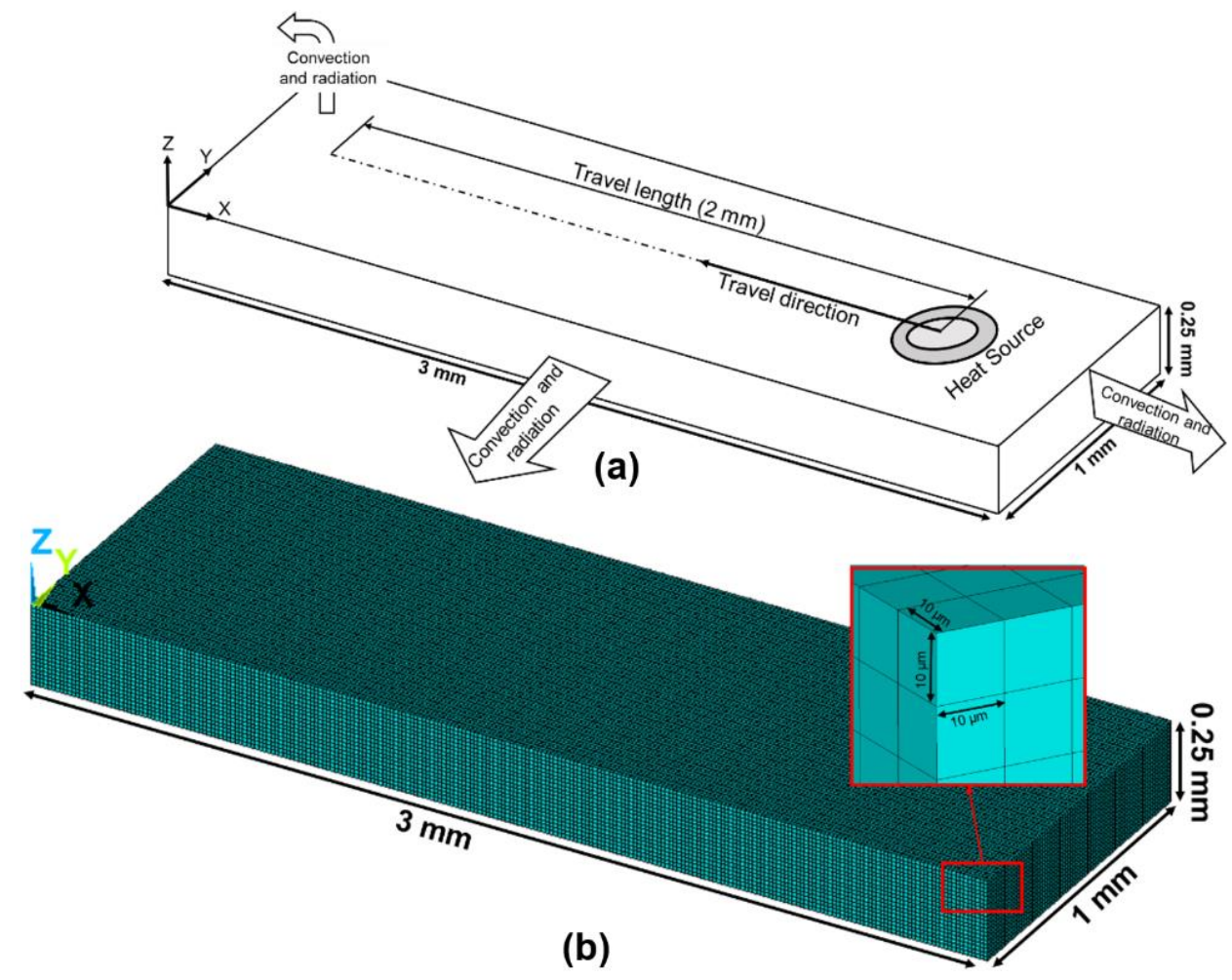

Figure 1. Construction of 3D geometry used for simulation (a) schematic and (b) meshed geometry of substrate material. 


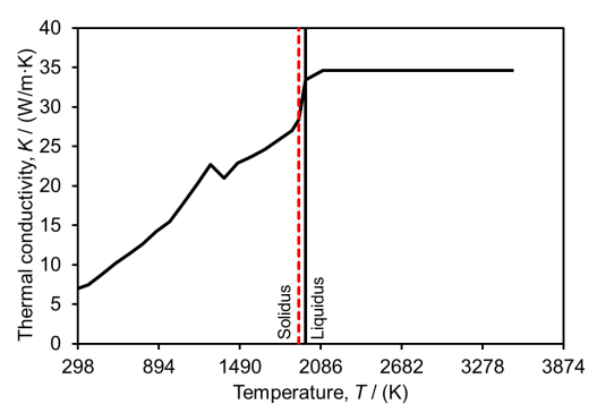

(a)

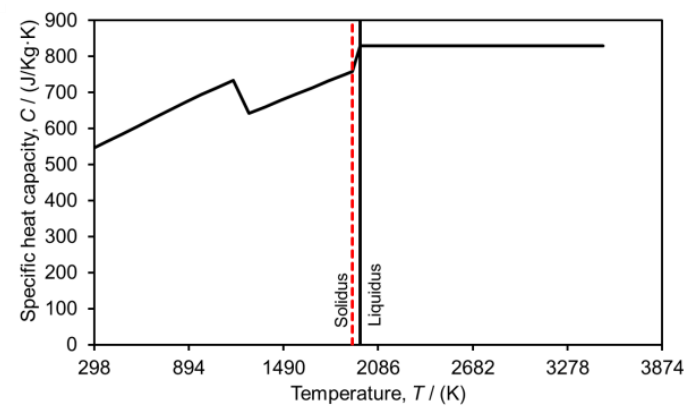

(b)

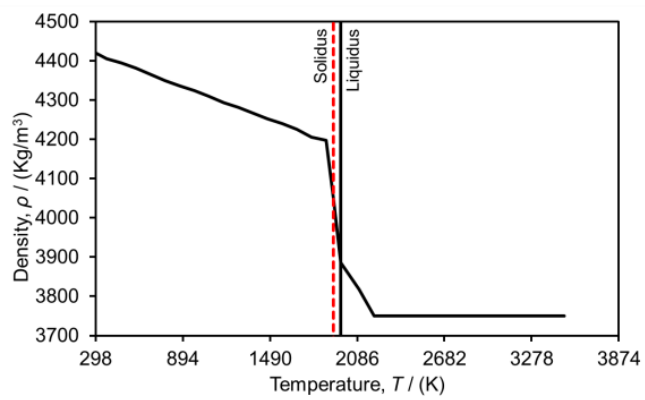

(c)

Figure 2. Thermophysical material properties such as (a) thermal conductivity, (b) specific heat capacity and (c) density of Ti-6Al-4V. 
Temperature,

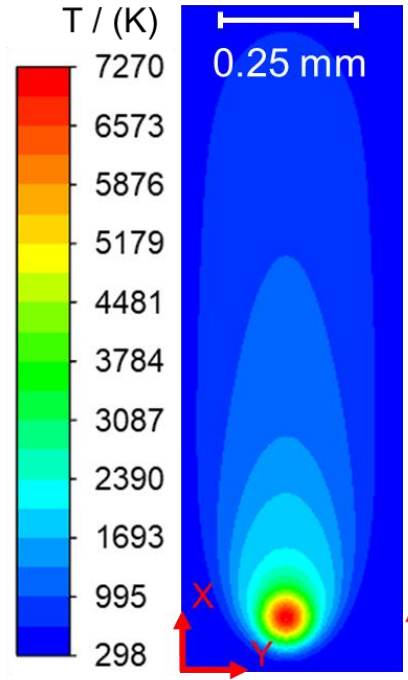

(a)

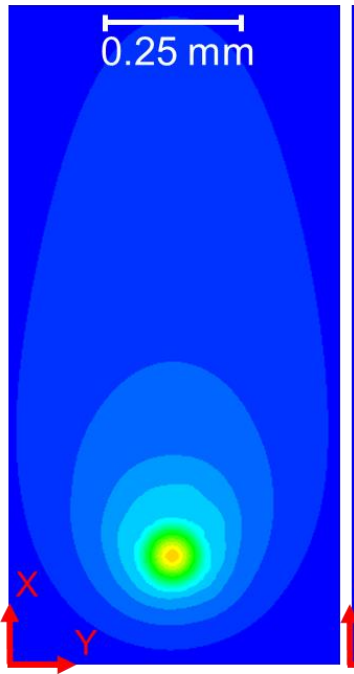

(b)

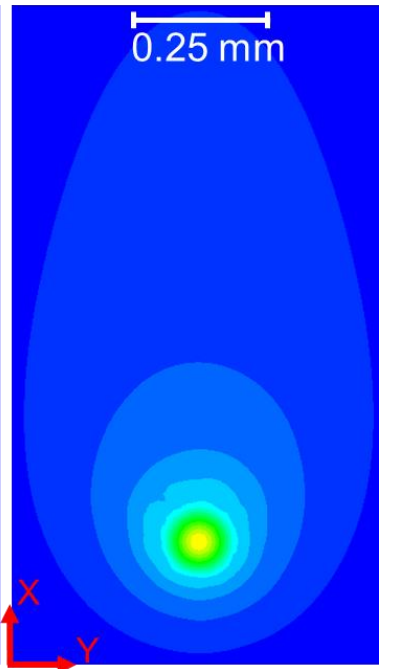

(c)

Figure 3. Simulated temperature distributions using CFD model with different surface tension gradients: (a) $0 \mathrm{~N} / \mathrm{m} \cdot \mathrm{K}$, (b) $-0.26 \times 10^{-3} \mathrm{~N} / \mathrm{m} \cdot \mathrm{K}$ and (c) $-0.37 \times 10^{-3} \mathrm{~N} / \mathrm{m} \cdot \mathrm{K}$. 


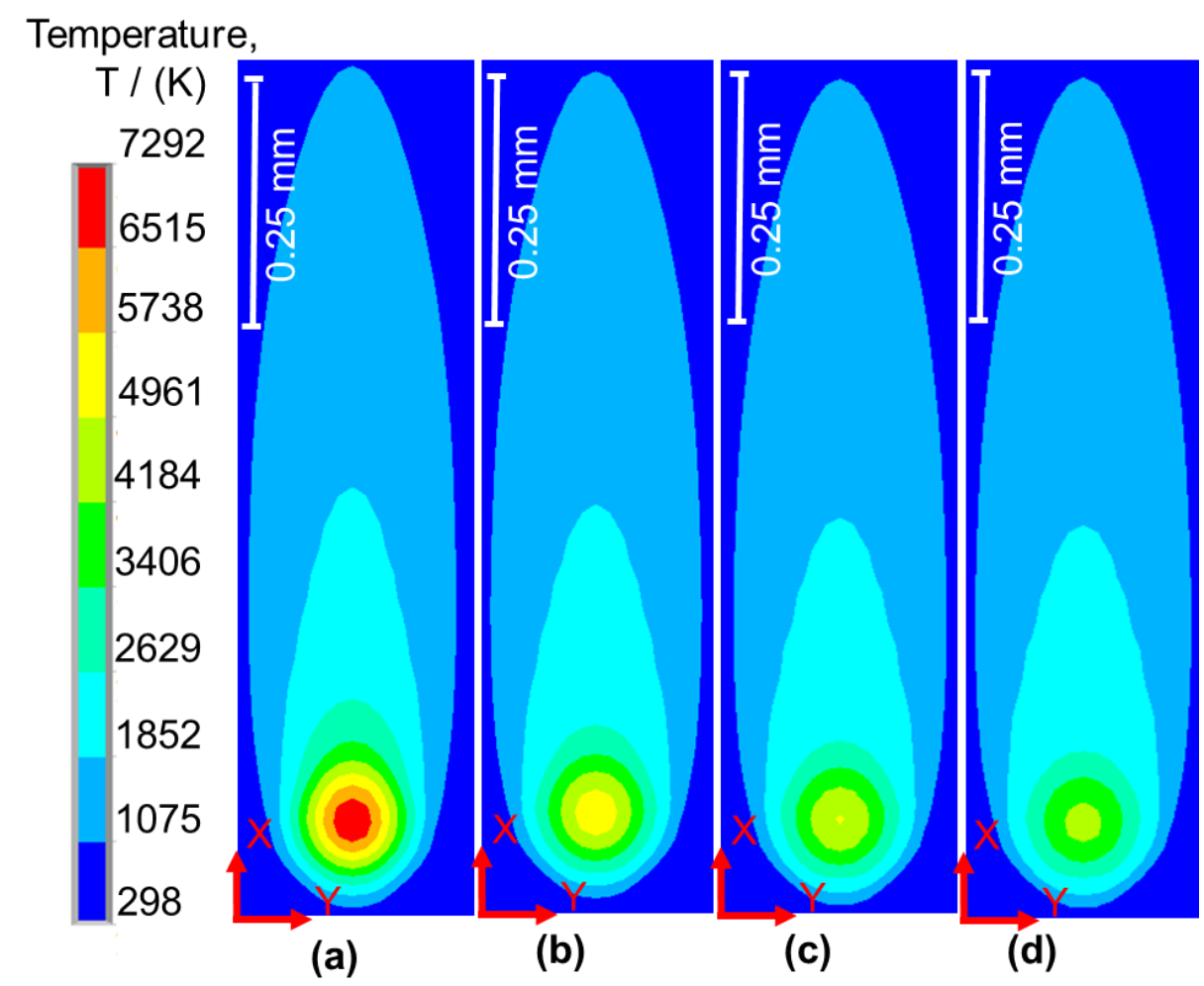

Figure 4. Simulated temperature distributions using the heat conduction model with different values of correction factor $C_{m}$ : (a) 1 , (b) 1.65 , (c) 2 and (d) 2.5 . 


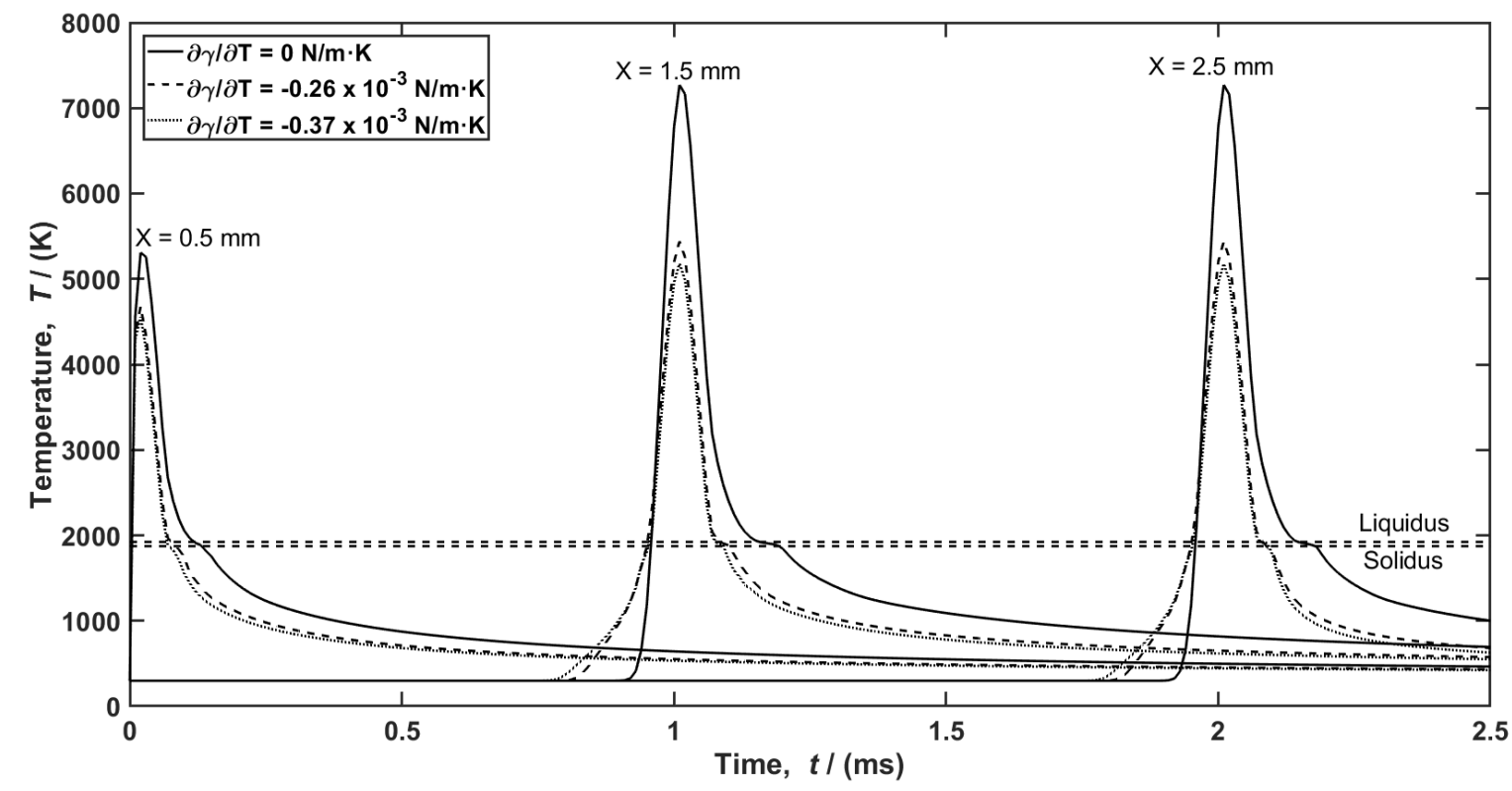

Figure 5. Thermal histories obtained for different values of surface tension gradient in the CFD model at different travel lengths along the path of the heat source: $0.5 \mathrm{~mm}, 1.5 \mathrm{~mm}$ and $2.5 \mathrm{~mm}$. 


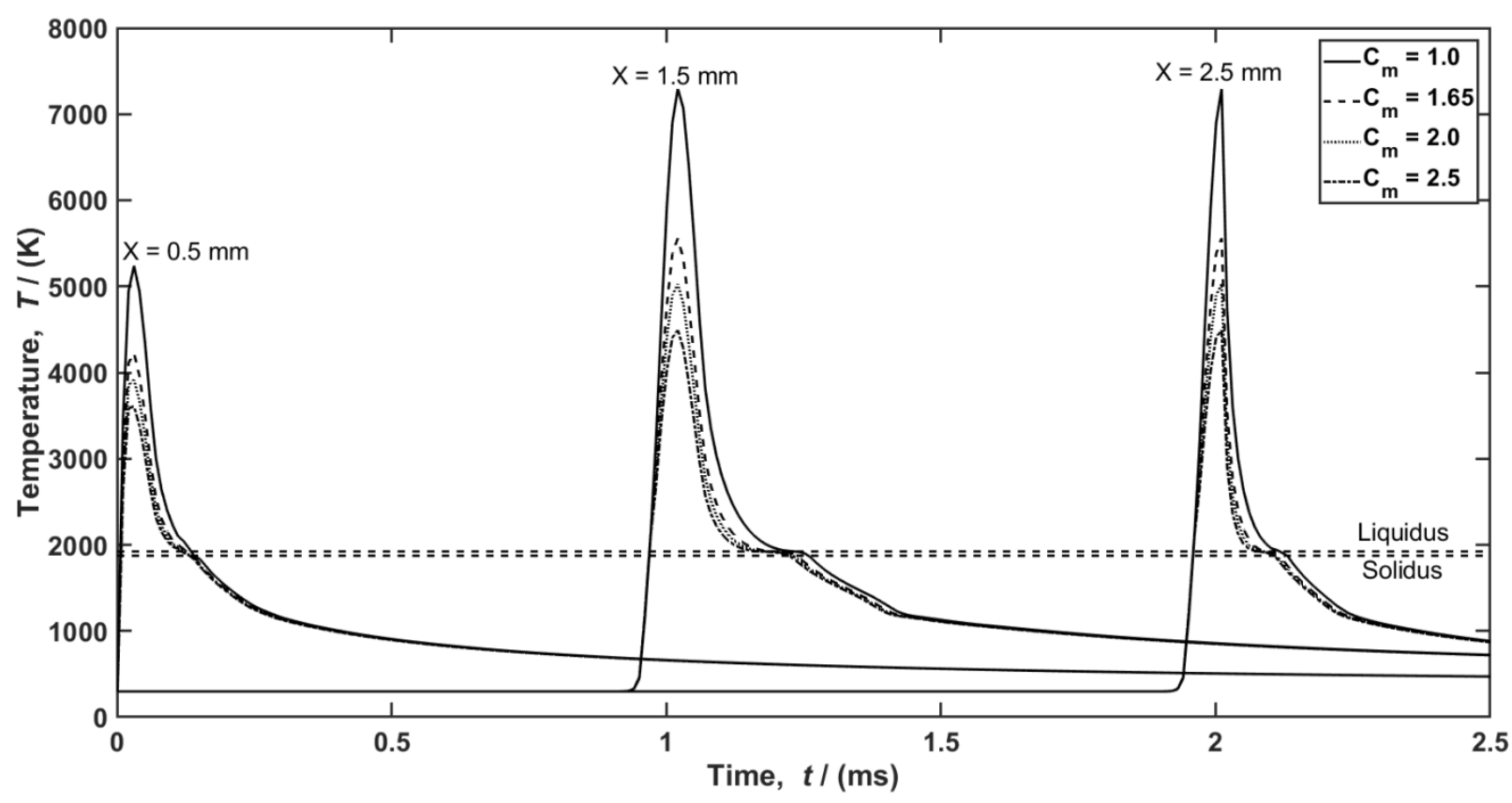

Figure 6. Thermal histories obtained for different values of correction factor in heat conduction model at different travel lengths along the path of the heat source: $0.5 \mathrm{~mm}, 1.5$ $\mathrm{mm}$ and $2.5 \mathrm{~mm}$. 


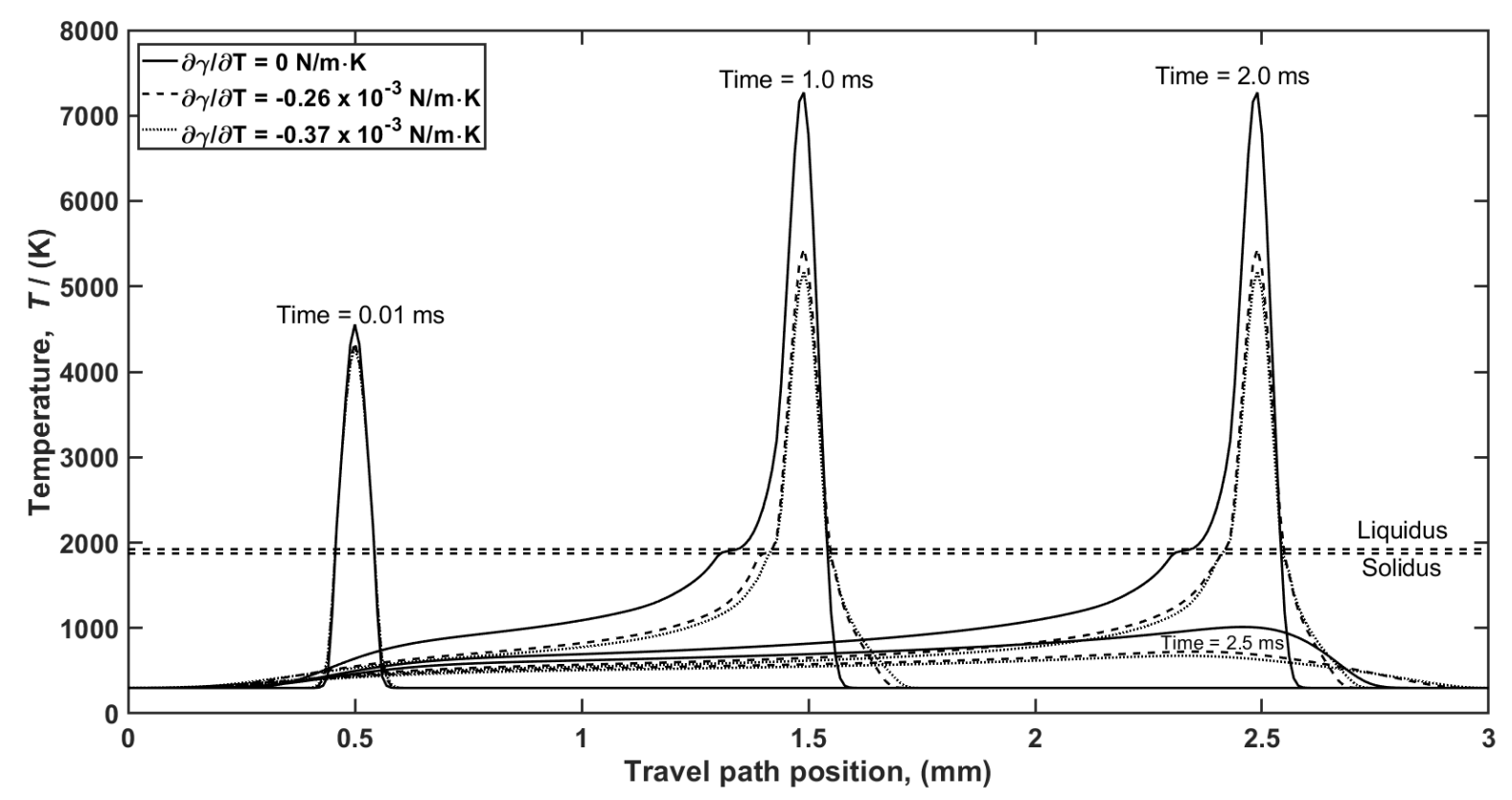

Figure 7. Comparison of thermal profiles obtained for different values of surface tension gradient in the CFD model and captured at $0.01 \mathrm{~ms}, 1 \mathrm{~ms}, 2 \mathrm{~ms}$ and $2.5 \mathrm{~ms}$ time intervals. 


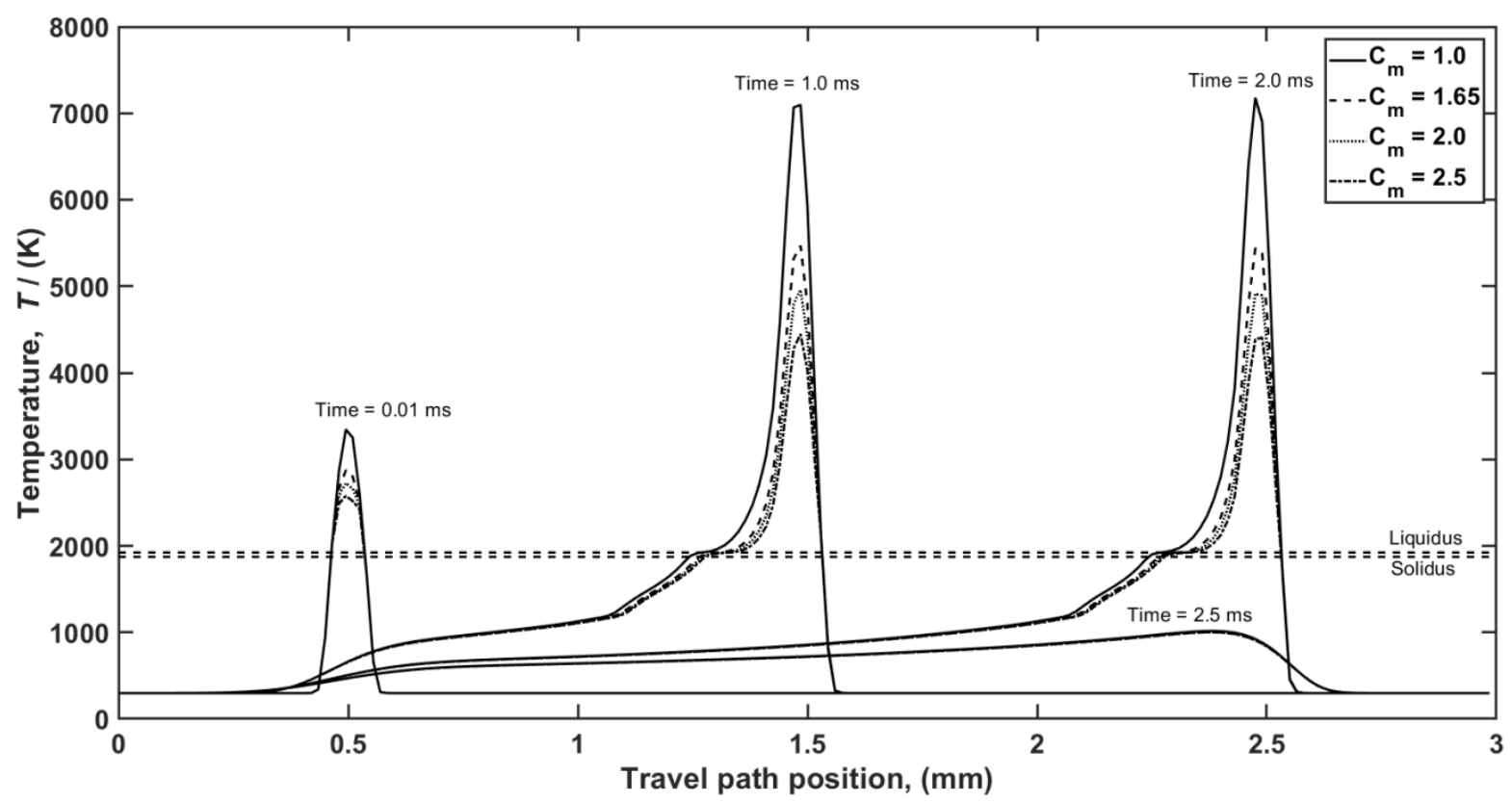

Figure 8. Comparison of thermal profile obtained for different values of correction factor used in the heat conduction model and captured at $0.01 \mathrm{~ms}, 1 \mathrm{~ms}, 2 \mathrm{~ms}$ and $2.5 \mathrm{~ms}$ time intervals. 


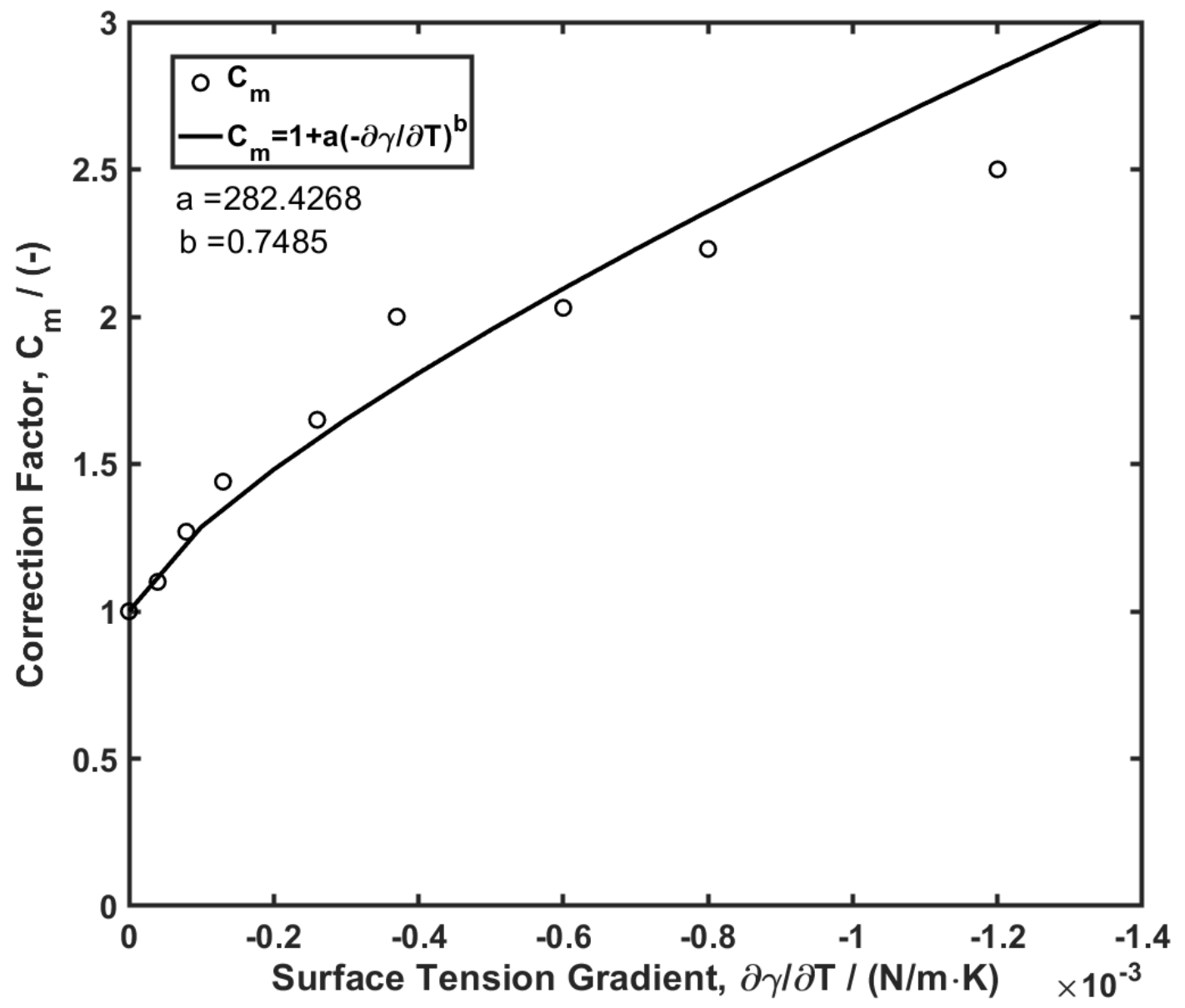

Figure 9. Correlation between the correction factor and surface tension gradient. 


\section{List of Figure captions}

Figure 1. Construction of 3D geometry used for simulation (a) schematic and (b) meshed geometry of substrate material.

Figure 2. Thermophyscial material properties such as (a) thermal conductivity, (b) specific heat capacity and (c) density of Ti-6Al-4V.

Figure 3. Simulated temperature distributions using CFD model with different surface tension gradients: (a) $0 \mathrm{~N} / \mathrm{m} \cdot \mathrm{K}$, (b) $-0.26 \times 10^{-3} \mathrm{~N} / \mathrm{m} \cdot \mathrm{K}$ and (c) $-0.37 \times 10^{-3} \mathrm{~N} / \mathrm{m} \cdot \mathrm{K}$.

Figure 4. Simulated temperature distributions using the heat conduction model with different values of correction factor $C_{m}$ : (a) 1 , (b) 1.65 , (c) 2 and (d) 2.5 .

Figure 5. Thermal histories obtained for different values of surface tension gradient in the CFD model at different travel lengths along the path of the heat source: $0.5 \mathrm{~mm}, 1.5 \mathrm{~mm}$ and $2.5 \mathrm{~mm}$.

Figure 6. Thermal histories obtained for different values of correction factor in heat conduction model at different travel lengths along the path of the heat source: $0.5 \mathrm{~mm}, 1.5$ $\mathrm{mm}$ and $2.5 \mathrm{~mm}$.

Figure 7. Comparison of thermal profiles obtained for different values of surface tension gradient in the CFD model and captured at $0.01 \mathrm{~ms}, 1 \mathrm{~ms}, 2 \mathrm{~ms}$ and $2.5 \mathrm{~ms}$ time intervals.

Figure 8. Comparison of thermal profile obtained for different values of correction factor used in the heat conduction model and captured at $0.01 \mathrm{~ms}, 1 \mathrm{~ms}, 2 \mathrm{~ms}$ and $2.5 \mathrm{~ms}$ time intervals.

Figure 9. Correlation between the correction factor and surface tension gradient. 